\title{
Review Perhitungan Biaya Wheeling (Wheeling Cost Calculation Review)
}

\author{
Yusuf Susilo Wijoyo ${ }^{1}$, Sasongko Pramono Hadi ${ }^{2}$, Sarjiya ${ }^{3}$
}

\begin{abstract}
Wheeling is a solution to the complexity of transmission network constructing problem. With the wheeling concept, a power plant owner can deliver electricity to its load without having to construct a transmission network. The owner of the power plant can utilize the transmission network belonging to other entities. The wheeling concept is an interesting thing in terms of increasing current renewable energy penetration. This is due to the construction of the transmission network, which is one of the obstacles in increasing renewable energy penetration. Fairness of wheeling costs is still one important topic. The discussion regarding wheeling costs emphasizes that the costs charged to each party involved can meet the fairness principle, which is in accordance with their respective contributions to the implementation of wheeling. Broadly speaking, research related to wheeling can be grouped into research for developing wheeling cost calculation methods and research for developing wheeling cost allocation methods. The development of the wheeling cost calculation method also includes the development of cost components that can be included in the cost calculation. This study summarizes the discussion of wheeling costs on three aspects, namely calculation methods, cost components, and cost allocation mechanisms.
\end{abstract}

Intisari-Wheeling merupakan solusi dari kompleksnya permasalahan pembangunan jaringan transmisi. Dengan konsep wheeling, pemilik pembangkit dapat menyalurkan tenaga listrik ke bebannya tanpa harus membangun jaringan transmisi. Pemilik pembangkit tersebut dapat memanfaatkan jaringan transmisi milik entitas lain. Konsep wheeling menjadi suatu hal yang menarik dalam kaitannya dengan peningkatan penetrasi energi terbarukan saat ini. Hal ini disebabkan pembangunan jaringan transmisi merupakan salah satu kendala dalam peningkatan penetrasi energi terbarukan. Fairness pada biaya wheeling sampai saat ini masih menjadi salah satu topik penting. Bahasan terkait biaya wheeling menitikberatkan agar biaya yang dibebankan pada setiap pihak yang terlibat dapat memenuhi kaidah fairness, yaitu sesuai dengan kontribusinya masing-masing pada implementasi wheeling. Secara garis besar, penelitian terkait wheeling dapat dikelompokkan menjadi penelitian untuk pengembangan metode perhitungan biaya wheeling dan penelitian untuk pengembangan metode alokasi biaya wheeling. Pengembangan metode perhitungan biaya wheeling juga mencakup pengembangan komponen biaya yang dapat dimasukkan dalam perhitungan biaya. Makalah ini merangkum pembahasan biaya wheeling pada tiga aspek, yaitu metode perhitungan, komponen biaya, dan mekanisme alokasi biaya.

Kata Kunci-Wheeling, Fairness, Alokasi Biaya.

1,2,3 Departemen Teknik Elektro dan Teknologi Informasi Fakultas Teknik Universitas Gadjah Mada, Jl. Grafika No 2 Kampus UGM Yogyakarta 55281 INDONESIA (tlp: 0274-552 305; fax: 0274547506; e-mail: yusufsw@ugm.ac.id, sasongko@ugm.ac.id, sarjiya@ugm.ac.id)

\section{Pendahuluan}

Pemanfaatan energi terbarukan pada sektor tenaga listrik pada saat ini mengalami perkembangan yang pesat. Statistik tahun 2019 menunjukkan bahwa pemanfaatan energi terbarukan meningkat sebesar $14,5 \%$ dan porsi penggunaan energi terbarukan pada pembangkitan tenaga listrik juga mengalami peningkatan dari 8,4\% menjadi 9,3\% [1]. Salah satu karakteristik energi terbarukan yaitu tergantung pada lokasi energi primer yang digunakan [2]. Dengan demikian, dibutuhkan jaringan transmisi untuk menyalurkan produksinya ke pusat beban [3]. Pembuatan jaringan transmisi ini melibatkan aspek yang sangat kompleks dengan interaksi antar aspek yang kompleks pula [4]. Permasalahan pada pembuatan jaringan transmisi ini dapat menghambat perkembangan pemanfaatan energi terbarukan.

Wheeling telah menjadi solusi bagi pemilik pembangkit pada permasalahan pembangunan jaringan transmisi. Skema ini sangat bermanfaat pada pemilik pembangkit yang tidak memiliki jaringan transmisi sendiri untuk menyalurkan produksinya pada beban yang dimilikinya. Wheeling ini juga sangat membantu peningkatan penetrasi energi terbarukan yang saat ini sedang berkembang pesat [5].

Wheeling saat ini dipandang dari beragam perspektif sehingga memiliki beberapa definisi [6]. Wheeling didefinisikan sebagai penyaluran tenaga listrik dari penjual kepada pembeli menggunakan jaringan transmisi yang dimiliki oleh pihak ketiga [6]. Definisi lainnya adalah pemakaian fasilitas jaringan transmisi maupun distribusi untuk menyalurkan tenaga listrik milik pihak lain [7]. Terminologi lainnya yaitu injeksi tenaga listrik pada salah satu titik jaringan atau lebih dengan disertai pengambilan tenaga listrik pada satu titik atau lebih lainnya secara simultan [8]. Wheeling didefinisikan pula sebagai transfer tenaga listrik melalui jaringan transmisi maupun distribusi dari satu area pelayanan utilitas ke area pelayanan utilitas lainnya [9].

Perhitungan biaya wheeling banyak menjadi objek diskusi sampai saat ini [6]. Pokok permasalahan diskusi perhitungan biaya wheeling terletak pada masalah fairness biaya untuk pihak-pihak yang terkait [9]-[22]. Upaya pengembangan untuk meningkatkan fairness biaya tersebut dapat dikelompokkan menjadi tiga aspek, yaitu melalui metode perhitungan, komponen yang masuk dalam perhitungan, dan mekanisme alokasi biaya pada pihak yang terlibat.

\section{Metode Perhitungan}

Metode perhitungan biaya wheeling mengalami banyak perkembangan sejak skema ini muncul. Prinsip-prinsip metode untuk mengevaluasi biaya wheeling berdasarkan marginal rate dipaparkan pada [23]. Metode ini memungkinkan implementasi 
wheeling antarutilitas dengan koordinasi yang lebih baik. Namun, metode ini belum dapat mendukung implementasi spot pricing. Klasifikasi metode perhitungan wheeling telah dipublikasikan [24]. Klasifikasi metode perhitungan wheeling pada penelitian tersebut yaitu embedded cost, short run marginal cost, long run marginal cost, dan long run fully incremental cost. Embedded cost menghitung biaya wheeling pada jaringan transmisi karena penggunaannya secara umum. Biaya ini yaitu biaya modal dan rerata biaya perawatan serta operasional di luar biaya produksi. Embedded cost terdiri atas postage stamp, contract path, boundary flow, dan line to line method. Perhitungan short run marginal cost didasarkan pada perubahan biaya yang dalam hal ini identik dengan biaya variabel (dalam $\$ / \mathrm{kWh}$ ). Long run incremental cost dihitung dengan memasukkan biaya investasi karena adanya operasi wheeling dan juga memasukkan perubahan biaya operasi pada sistem existing-nya. Metode ini terdiri atas standard long run incremental cost yang berbasis perencanaan existing dan long run fully incremental cost yang berbasis perencanaan karena adanya tambahan wheeling. Beberapa metode perhitungan biaya wheeling yang umum digunakan pada perusahaan utilitas juga telah dibahas [25]. Penelitian ini juga menjelaskan isu-isu utama pada implementasi setiap metode di industri. Adapun studi kasus implementasi wheeling pada Sistem Jamali dilakukan pada [26]. Pada penelitian ini, dibandingkan metode perhitungan wheeling dengan power flow dan tanpa power flow.

Perhitungan biaya wheeling dengan pendekatan yang berbeda antara operating cost dan embedded cost telah dilakukan [27]. Operating cost dalam hal ini mempertimbangkan ancillary service yang disediakan pemilik jaringan kepada pelaku wheeling. Pemakaian kapasitas yang berbeda-beda antarpengguna jaringan transmisi juga dimasukkan dalam perhitungan ini.

Marginal cost pada [24] merupakan pengembangan dari publikasi perhitungan biaya wheeling berbasis marginal cost yang telah dilakukan sebelumnya [7], [17]. Perhitungan biaya wheeling berbasis metode short run marginal cost dengan memperhatikan marginal generating cost, losses, kualitas suplai pembangkitan, dan kualitas suplai pada jaringan dilakukan pada [28]. Biaya wheeling dalam hal ini dapat bernilai negatif dan dapat pula bernilai positif. Bernilai negatif berarti keberadaan pelaku wheeling telah memperbaiki losses sistem dan demikian pula sebaliknya. Perhitungan biaya wheeling pada penelitian ini dapat menunjukkan kontribusi pelaku wheeling pada sistem dengan baik. Algoritme untuk menentukan kelayakan biaya wheeling berdasarkan available transfer capability dengan menggunakan basis metode short run marginal cost juga telah dikembangkan [29]. Metode ini dapat memberikan informasi kepada pemilik pembangkit wheeling untuk memilih lokasi sekaligus informasi kepada pemilik beban wheeling untuk memilih pembangkit yang paling menguntungkan. Konsep metode long run marginal cost untuk sistem distribusi yang dapat mencerminkan biaya atau keuntungan jangka panjang dari penggunaan jaringan untuk implementasi wheeling dilakukan pada [30]. Alokasi biaya pada perhitungan biaya wheeling ini memperhatikan pula aliran daya reaktif. Dengan demikian, perhitungan revenue requirement dapat menghasilkan nilai yang lebih baik. Metode perhitungan biaya wheeling pada sistem interkoneksi multiarea berbasis long run marginal cost dipublikasikan pada [31]. Kontribusi pelaku wheeling dapat terlihat melalui perhitungan ini. Di samping itu, perhitungan harga melalui metode ini dapat memberikan nilai harga yang stabil untuk jangka panjang. Perhitungan dengan metode long run incremental cost dengan mempertimbangkan kapasitas jaringan yang tidak digunakan dilakukan pada [32]. Metode ini tidak memerlukan informasi rencana pengembangan pembangkit selanjutnya dalam perhitungannya

Metode line to line method pada [24] merupakan pengembangan metode MW mile yang pertama kali diperkenalkan pada [18]. Dengan metode ini, kontribusi pelaku wheeling terhadap pemakaian jaringan dapat diketahui. Konsep kombinasi perhitungan biaya wheeling antara MW mile dan postage stamp dipublikasikan pada [33]. Metode ini dapat memperbaiki hasil perhitungan biaya wheeling dengan MW mile yang cenderung kurang memenuhi revenue requirement. Konsep ini juga memperhitungkan biaya pada transmisi yang tidak secara langsung terlibat pada operasi wheeling. Metode contract path dan MW mile dengan identifikasi jalur transaksi berbasis analisis sensitivitas dikembangkap pada [14]. Metode ini memungkinkan identifikasi jalur wheeling yang paling ekonomis, sehingga dapat memperbaiki kelemahan dari metode contract path. Perhitungan biaya wheeling berdasarkan metode MW mile dengan memanfaatkan hasil simulasi short circuit untuk proses alokasi biaya dipaparkan pada [34]. Metode ini memiliki akurasi dan fleksibilitas yang lebih baik dari metode MW mile sebelumnya. Modifikasi pada metode perhitungan MW mile telah dilakukan pada [35]. Modifikasi dilakukan dengan memasukkan losses dan faktor daya dalam perhitungan. Pengembangan metode MW mile dengan mempertimbangkan kontribusi pelaku wheeling pada arah aliran daya di jaringan eksisting dilakukan pada [36]. Pada penelitian ini terdapat tiga pendekatan perhitungan dalam kaitannya dengan arah aliran daya, yaitu reserve, absolute, dan dominant. Modifikasi metode MW mile dengan memasukkan daya reaktif sehingga dinamakan metode MVA mile dipublikasikan pada [37]. Metode MVA mile ini untuk selanjutnya dikembangkan dengan mempertimbangkan perbedaan biaya pada jaringan transmisi [38].

Implementasi wheeling untuk dikombinasikan dengan layanan grid juga telah diteliti [39]. Penelitian ini mempertimbangkan perpindahan antara pemakaian dari grid dan sebaliknya, yaitu dari pemakaian pembangkit sendiri dalam perhitungan biaya wheeling. Komparasi biaya wheeling yang timbul pada transaksi di transmisi, pada tipe transaksi transmisi, dan pada metode perhitungan biaya transmisi, dideskripsikan pada [40]. Referensi [41] membahas penentuan titik penyambungan dan kapasitas maksimum independent power producer yang optimum menggunakan new hybrid particle swarm optimization dengan Cauchy mutation. Adapun analisis terhadap metode perhitungan wheeling, baik secara umum dan spesifik, dikaitkan dengan distributed generation, dilakukan pada [42]. Efek wheeling pada keandalan sistem, termasuk cost dan benefit-nya, diteliti pada [43]. Model reduksi area loop 
wheeling dipublikasikan pada [44]. Perhitungan pada publikasi ini hanya dititikberatkan pada area yang secara langsung terlibat dalam kontrak bilateral wheeling.

Metode optimasi untuk multiarea wheeling dikembangkan pada [45]. Adapun pemanfaatan Optimal Power Flow (OPF) untuk perhitungan biaya wheeling dilakukan pada [46]. Penelitian tersebut melakukan modifikasi OPF untuk implementasi wheeling, yaitu dengan tidak hanya memasukkan biaya pembangkitan, tetapi juga memasukkan biaya transmisi. Reformulasi OPF untuk wheeling dengan konsep baru dalam memodelkan kelompok generator dan beban dilakukan pada [47]. Referensi [48] memperkenalkan perhitungan biaya wheeling dengan evolutionary programming berbasis OPF. Adapun perhitungan wheeling dengan model hibrida yang mengintegrasikan pendekatan klasik dan pendekatan artificial intelligence berdasarkan OPF diperkenalkan pada [49].

\section{KOMPONEN BIAYA}

Identifikasi aspek yang dipertimbangkan untuk masuk menjadi komponen biaya wheeling merupakan salah satu upaya untuk meningkatkan kelayakan biaya wheeling. Hal ini merupakan titik tengah antara kepentingan pelaku wheeling dengan pemilik jaringan transmisi. Salah satu kendala dalam memasukkan aspek-aspek ini yaitu terkait kompleksitas perhitungannya.

Referensi [50] membahas aspek dasar dalam penyusunan harga layanan jaringan transmisi. Publikasi ini memaparkan konsep penyusunan harga layanan transmisi berdasarkan biaya layanan transmisi. Penyusunan konsep perhitungan biaya transmisi berdasarkan kapasitas yang digunakan disusun pada [51]. Identifikasi pemakaian kapasitas dilakukan berdasarkan data operasi tahunan. Metode ini dapat menjaga keseimbangan investasi jaringan transmisi karena implementasi wheeling. Referensi [52] menyusun struktur komponen biaya wheeling berikut simulasinya. Komponen yang dimasukkan termasuk kontingensi dengan beberapa penyederhanaan. Perhitungan tarif listrik dengan mempertimbangkan implementasi wheeling dilakukan pada [15]. Modifikasi perhitungan economic dispatch dengan memasukkan biaya wheeling sebagai salah satu konsideransnya dilakukan pada [53]. Algoritma genetika digunakan untuk optimisasi dalam penelitian ini.

Perhitungan biaya wheeling berdasarkan marginal cost dengan memperhitungkan biaya daya aktif maupun reaktif yang muncul saat perpindahan transaksi antar pelaku wheeling diteliti pada [54]. Perhitungan tersebut diimplementasikan pada sistem spot pricing. Penelitian lain mendefinisikan perhitungan biaya wheeling berdasarkan pengukuran homogen untuk pemakaian transmisi, baik daya aktif maupun reaktif [55]. Metode ini dapat memberikan hasil perhitungan yang dapat menutup seluruh biaya investasi, operasi, perawatan, dan pengembangan. Perhitungan marginal cost dengan memasukkan aliran daya reaktif sebagai komponen biaya dilakukan pada [56]. Perhitungan tersebut juga memasukkan aspek sensitivitas dengan MW mile.

Sebuah publikasi menyusun perhitungan marginal cost pada wheeling dengan memasukkan aspek sekuriti jaringan [31]. Adapun penelitian lainnya memasukkan aspek kontingensi dalam perhitungan biaya wheeling [57]. Aspek keandalan dimasukkan sebagai komponen biaya wheeling pada [58]. Sedangkan indikator-indikator keandalan yang dapat dimasukkan sebagai komponen biaya wheeling dipaparkan pada [59].

Komponen perbedaan magnitude aliran daya dimasukkan sebagai salah satu komponen biaya wheeling pada [60]. Adapun pada [46] dilakukan penyusunan perhitungan biaya yang timbul pada sistem existing karena wheeling dengan memasukkan deviasi biaya pembangkitan dan biaya transmisi. Penelitian lainnya menyusun perhitungan biaya wheeling dengan memasukkan aspek probabilitas biaya produksi [61]. Probabilitas biaya produksi tersebut merupakan probabilitas dari kesiapan pembangkit untuk beroperasi.

Faktor daya dimasukkan dalam perhitungan biaya wheeling pada [62]. Faktor daya dan aspek losses pada [63] dimasukkan dalam perhitungan biaya. Referensi [64] membahas dampak operasi wheeling pada utilitas existing dari perspektif losses transmisi, profil tegangan, dan kongesti jaringan. Biaya kapasitas, kongesti, dan losses pada jaringan dimasukkan sebagai komponen biaya wheeling pada [65]. Penyusunan estimasi maksimum kapasitas transfer daya aktif dan daya reaktif untuk operasi wheeling pada sistem existing tanpa memerlukan penjadwalan ulang pembangkit juga telah dilakukan [66]. Penyusunan model perhitungan biaya wheeling yang memasukkan komponen biaya waktu pemakaian dan kualitas daya dipublikasikan pada [67]. Referensi [68] melakukan analisis pada kontrak wheeling bilateral dan multilateral berdasarkan aliran daya pada kondisi base load, increasing load, dan peak load, baik untuk kondisi saat ada implementasi wheeling maupun tidak ada wheeling. Operating costs, opportunity cost, existing system cost reinforcement cost, dan share in the avoided cost of generation dimasukkan sebagai komponen biaya wheeling pada [69]. Penelitian ini berlatar belakang implementasi wheeling pada sistem interkoneksi Afrika Barat.

Referensi [70] membahas beberapa pertimbangan dalam optimasi keuntungan, antara lain terkait keseimbangan social welfare sebagai dasar perhitungan harga wheeling, perubahan pada economic dispatch, dan terjadinya bottle neck pada jaringan. Metode ini menggunakan algoritme genetika untuk optimisasinya dan perhitungan biaya wheeling menggunakan MW mile. Referensi [71] memanfaatkan wheeling untuk diintegrasikan dalam mekanisme sinkronisasi optimasi keuntungan penyediaan listrik. Sinkronisasi optimasi sektor pembangkitan dengan transmisi dengan multi echelon priced based dynamic economic dispatch. Biaya di jaringan transmisi tersebut diasumsikan sebagai biaya losses dan biaya wheeling. Biaya wheeling dihitung dengan metode MW mile (reverse dan absolute). Dalam publikasi ini, wheeling digunakan untuk perhitungan transfer energi antar zona.

\section{MeKanisme AlOKasi BiayA}

Biaya wheeling dapat terdiri atas fix cost maupun variable cost. Hal tersebut akan tergantung pada metode perhitungan yang digunakan. Alokasi fix cost biaya wheeling identik dengan mekanisme alokasi biaya jaringan transmisi pada umumnya. 


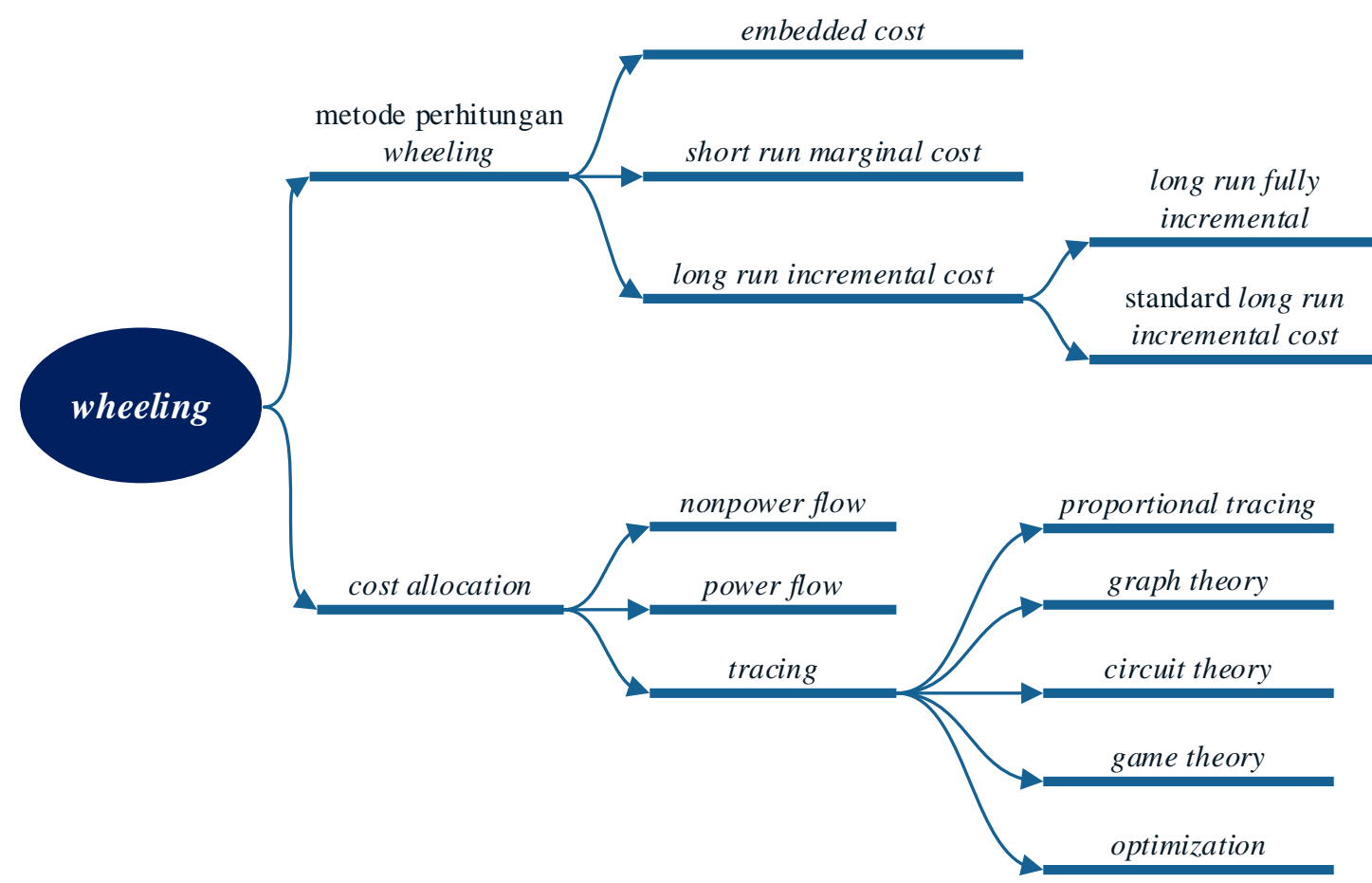

Gbr. 1 Pemetaan topik penelitian terkait wheeling.

Penyusunan metode untuk alokasi fix cost transmisi pada operasi wheeling berdasarkan pola pemakaian dengan memanfaatkan skema nucleolus pada game theory dilakukan pada [72]. Metode alokasi fix cost dengan metode tracing berbasis optimasi juga telah diperkenalkan [73]. Optimasi yang dilakukan adalah dalam menentukan kontribusi setiap pembangkit pada setiap bus. Alokasi fix cost dengan berbasis medan magnetik yang muncul di setiap jaringan transmisi dipublikasikan pada [74]. Referensi [75] menyusun review metode alokasi fix cost dengan membandingkan antara metode embedded cost dan metode MW mile beserta turunannya. Referensi [76] menyusun metode alokasi biaya transaksi pengguna jaringan transmisi secara proporsional terhadap incremental power flow dari tiap pengguna. Metode ini merupakan modifikasi MW mile untuk aplikasi multiple wheeling transaction.

Referensi [77] menyusun model power tracing yang memungkinkan mekanisme perhitungan kontribusi biaya losses karena suatu pembangkit. Sebuah penelitian pada tahun 1997 menyusun metode tracing berdasarkan konsep proporsionalitas [78]. Pengembangan algoritme yang efisien untuk menentukan kontribusi suatu generator pada penggunaan transmisi dan losses sistem memanfaatkan graph theory dilakukan pada [79]. Graph theory untuk alokasi biaya penggunaan jaringan transmisi dan losses juga dilakukan pada [80]. Pada penelitian ini, dilakukan modifikasi pada matriks Kirchoff sehingga komputasi menjadi lebih efisien. Referensi [81] melakukan penelitian metode alokasi kontribusi setiap pelaku wheeling pada kongesti, memanfaatkan indeks kontribusi flexible alternating current transmission system. Penyusunan metode alokasi losses dari output generator berbasis generalized generation distribution factors dan modifikasi metode power transfer distribution factors dilakukan pada [82]. Sedangkan pembahasan perhitungan biaya jaringan transmisi untuk wheeling yang mempertimbangkan kongesti pada saat peak dan off peak dengan alokasi menggunakan power transfer distribution factor dilakukan pada [16].

Referensi [20] menyusun suatu model alokasi biaya transmisi dengan metode usage based. Metode ini berbasis zbus dan contractual obligation. Dengan metode ini, dimungkinkan perhitungan kontribusi generator dan demand secara simultan. Perhitungan alokasi biaya transmisi dengan memperhitungkan fluktuasi pembebanan transmisi dilakukan pada [83]. Hal ini sebagai dasar perhitungan skema insentif bagi pembangkit energi terbarukan yang jauh dari beban. Referensi [84] menyusun pendekatan untuk alokasi losses transmisi secara optimal diantara utilitas yang terlibat wheeling dengan memanfaatkan loss ratio constraint. Metode alokasi biaya transmisi yang terkait losses daya aktif dilakukan pada [85]. Dalam hal ini, metode yang dilakukan berdasarkan prinsip proportional sharing. Penelitian lain melakukan pengembangan metode alokasi losses daya aktif [21]. Metode yang dikembangkan tersebut tidak memerlukan konversi pada sistem seperti pada metode terdahulu, yaitu konversi agar daya aktif di kedua ujung setiap jaringan transmisi sama. Adapun metode alokasi biaya wheeling untuk daya reaktif yang timbul dilakukan pada [86]. 
Pemanfaatan artificial intelligence untuk alokasi daya aktif dilakukan pada [87]. Sedangkan penelitian penggunaan flower pollination algorithm untuk alokasi kontribusi suplai daya aktif pada sistem sebagai dasar perhitungan biaya dilakukan pada [88]. Alokasi biaya wheeling berbasis MW mile dengan algoritme genetika dilakukan pada [89]. Pemanfaatan gravitational search algorithm untuk alokasi losses pada jaringan transmisi dilakukan pada [90]. Penelitian pemanfaatan metode min-max fairness untuk alokasi biaya jaringan dilakukan pada [91]. Adapun penelitian metode efisiensi komputasi untuk perhitungan min-max fair power flow tracing dilakukan pada [92]. Dengan metode, ini jumlah variabel dapat direduksi secara signifikan.

\section{Isu UtAma WHEeLING}

Publikasi-publikasi terkait wheeling menunjukkan bahwa fairness pada biaya wheeling merupakan pokok dari permasalahan. Penelitian-penelitian yang dikembangkan merupakan upaya untuk memperoleh biaya wheeling yang memenuhi kaidah fairness. Berdasarkan penelitian yang menjadi referensi, secara garis besar topik penelitian terkait wheeling dapat dipetakan seperti pada Gbr. 1.

Pemetaan pada Gbr. 1 tersebut memperlihatkan bahwa penelitian wheeling dapat dikelompokkan menjadi pengembangan metode perhitungan dan pengembangan metode alokasi biaya. Basis untuk pengembangan metode perhitungan yaitu embedded cost, short run marginal cost, dan long run incremental cost. Pengembang-an metode perhitungan bertujuan agar kepentingan baik dari pemilik jaringan transmisi maupun pelaku wheeling dapat terwakili. Embedded cost menitikberatkan biaya tetap jaringan transmisi sebagai dasar perhitungan biaya wheeling. Short run marginal cost menggunakan biaya tetap jaringan transmisi dan biaya operasi sistem jangka pendek sebagai dasar biaya wheeling. Adapun long run incremental cost, selain memperhatikan biaya tetap, juga memperhatikan biaya operasi dalam jangka panjang.

Pengembangan metode alokasi biaya bertujuan agar beban biaya yang ditanggung pelaku wheeling dapat sesuai kontribusinya. Metode alokasi ini secara garis besar dapat dibagi menjadi non-power flow, power flow, dan tracing. Nonpower flow tidak memerlukan bantuan analisis power flow untuk alokasinya. Adapun metode power flow memerlukan bantuan analisis power flow untuk proses alokasi biaya. Perbandingan hasil power flow sebelum dan sesudah implementasi wheeling menjadi dasar alokasi biaya ini. Adapun metode tracing melakukan alokasi biaya wheeling memanfaatkan mekanisme tracing untuk kontribusi setiap pelaku wheeling pada setiap bus dan pada setiap jaringan transmisi.

\section{KESIMPULAN}

Diskusi terkait wheeling telah mengalami banyak pengembangan. Peningkatan fairness biaya wheeling menjadi topik utama dalam diskusi pengembangan ini. Biaya wheeling diharapkan dapat mencerminkan biaya sesuai kontribusinya, baik dari sisi pemilik jaringan transmisi maupun pelaku wheeling. Pengembangan ini mengikuti kondisi riil perkembangan pasar ketenagalistrikan. Upaya untuk meningkatkan fairness dilakukan melalui tiga pendekatan, yaitu melalui pengembangan metode, komponen biaya, dan mekanisme alokasi.

\section{REFERENSI}

[1] B. Dudley, "BP Statistical Review of World Energy,” BP, London, UK 2019.

[2] L. Hirth, F. Ueckerdt, dan O. Edenhofer, "Integration Costs Revisited An Economic Framework for Wind and Solar Variability,” Renew. Energy, Vol. 74, hal. 925-939, 2015.

[3] R. Sims, P. Mercado, W. Krewitt, G. Bhuyan, D. Flynn, H. Holttinen, G. Jannuzzi, S. Khennas, Y. Liu, M. O’Malley, L.J. Nilsson, J. Ogden, K. Ogimoto, H. Outhred, Ø. Ulleberg, F. van Hulle, "Integration of Renewable Energy into Present and Future Energy Systems," dalam IPCC Special Report on Renewable Energy Sources and Climate Change Mitigation, O. Edenhofer, R. Pichs-Madruga, Y. Sokona, K. Seyboth, P. Matschoss, S. Kadner, T. Zwickel, P. Eickemeier, G. Hansen, S. Schlömer, C. von Stechow, Eds., Cambridge, UK: Cambridge University Press, 2011, hal. 609-706.

[4] T.S. Kishore dan S.K. Singal, “Analysis of Investment Issues and Transmission Schemes for Grid Integration of Remote Renewable Energy Sources,” Int. J. Renew. Energy Res., Vol. 5, No. 2, hal. 483-490, 2015.

[5] J. Heeter, R. Vora, S. Mathur, P. Madrigal, S.K. Chatterjee, dan R. Shah, "Wheeling and Banking Strategies for Optimal Renewable Energy Deployment: International Experiences,” National Renewable Energy Laboratory, Golden, USA, Tech. Report, hal. 1-49, 2016.

[6] Y.R. Sood, N.P. Padhy, dan H.O. Gupta, "Wheeling of Power under Deregulated Environment of Power System: A Bibilographical Survey,” IEEE Power Eng. Rev., Vol. 22, No. 7, p. 58, 2002.

[7] H.M. Merril dan B.W. Erickson, "Wheeling Rates Based on Marginal Cost Theory,” IEEE Trans. Power Syst., Vol. 4, No. 4, hal. 1445-1451, 1989.

[8] A. Bashian, M. Hojat, M.H. Javidi, dan H. Golmohamadi, "SecurityBased Tariff for Wheeling Contracts Considering Fair Congestion Cost Allocation,” J. Control. Autom. Electr. Syst., Vol. 25, No. 3, hal. 368-380, 2014.

[9] K.H. Lalitha dan I.K. Kiran, "Comparison of Wheeling Cost using Power Flow Tracing Methods in Deregulated Electric Power Industry,” Int. J. Eng. Technol. Manag. Appl. Sci., Vol. 5, No. 6, hal. 861-870, 2017.

[10] M.Y. Hassan, N.H. Radzi, M.P. Abdullah, F. Hussin, dan M.S. Majid, "Wheeling Charges Methodology for Deregulated Electricity Markets using Tracing-based Postage Stamp Methods,” Int. J. Integr. Eng., Vol. 3, No. 3, hal. 39-46, 2011.

[11] B. Li, D.A. Robinson, dan A. Agalgaonkar, "Identifying The Wheeling Costs Associated with Solar Sharing in LV Distribution Networks in Australia using Power Flow Tracing and MW-Mile Methodology,” 2017 Australasian Universities Power Engineering Conference, AUPEC 2017, 2017, hal. 1-6.

[12] A. Saxena, S.N. Pandey, dan L. Srivastava, "DC-OPF Based Allocation of Wheeling Prices for Varying Contribution of Producers and Customers,” 1st IEEE International Conference on Power Electronics, Intelligent Control and Energy Systems, ICPEICES 2016, 2016, hal. 3-7.

[13] M. Murali, M.S. Kumari, dan M. Sydulu, “A Comparison of Fixed Cost Based Transmission Pricing Methods,” Electr. Electron. Eng., Vol. 1, No. 1, hal. 33-41, 2012.

[14] H. Hamada, H. Tanaka, dan R. Yokoyama, "Wheeling Charge Based on Identification of Transaction Paths in Deregulated Power Markets," Proc. Int. Univ. Power Eng. Conf., 2009, hal. 1-5.

[15] P. Payakkamas, A. Bangviwat, C. Menke, dan P. Trinuruk, "Price Determination of Electricity Supply in Thailand Based on Externalities, Wheeling Charges, and Losses," Sci. Technol. Asia, Vol. 22, No. 3, hal. 49-64, 2017.

[16] A. Bashian, T.S. Attar, M.H. Javidi, dan M. Hojat, "Determination of Tariff for Wheeling Contracts Considering Fairness Congestion Cost Allocation,” Proc. Power Energy Syst., 2011, hal. 1-6.

[17] M.C. Caramanis, R.E. Bohn, dan F.C. Schweppe, “The Cost of Wheeling 
and Optimal Wheeling Rates,” IEEE Trans. Power Syst., Vol. 1, No. 1, hal. 63-73, 1986.

[18] D. Shirmohammadi, P.R. Gribik, E.T.K. Law, J.H. Malinowski, dan R.E. O'Donnell, "Evaluation of Transmission Network Capacity Use for Wheeling Transactions,” IEEE Trans. Power Syst., Vol. 4, No. 4, hal. 1405-1413, 1989.

[19] Y. Xiao, X. Wang, X. Wang, dan C. Du, "Transmission Cost Allocation by Power Tracing Based Equivalent Bilateral Exchanges," CSEE $J$. Power Energy Syst., Vol. 2, No. 2, hal. 1-10, 2016.

[20] M.S.G. Smitha, P.V. Satyaramesh, dan P. Sujatha, "Usage Based Transmission Cost Allocation to Wheeling Transactions in Bilateral Markets,” J. Inst. Eng. Ser. B, Vol. 100, No. 1, hal. 23-31, 2018.

[21] A. Enshaee, G.R. Yousefi, dan A. Ebrahimi, "Allocation of Transmission Active Losses Through a Novel Power Tracing-Based Technique," IET Gener. Transm. Distrib., Vol. 12, No. 13, hal. 3201-3211, 2018.

[22] J. Hörsch, M. Schäfer, S. Becker, S. Schramm, dan M. Greiner, "Flow Tracing as a Tool Set for the Analysis of Networked Large-scale Renewable Electricity Systems," Int. J. Electr. Power Energy Syst., Vol. 96, hal. 390-397, 2018.

[23] S.P. Zhu, "Practice and Theory for Pricing Wheeled Power," IET Metering Appar. Tarif. Electr. Supply, Vol. 7, hal. 67-71, 1992.

[24] H.H. Happ, “Cost of Wheeling Methodologies," IEEE Trans. Power Syst., Vol. 9, No. 1, hal. 147-156, 1994.

[25] W.J. Lee, C.H. Lin, dan L.D. Swift, "Wheeling Charge Under a Deregulated Environment,” IEEE Trans. Ind. Appl., Vol. 37, No. 1, hal. 178-183, 2001.

[26] Hermawan dan T. Andromeda, "Comparison of Cost Estimation Methods in Power Wheeling for Java-Bali Interconnection System,” Proc. - 2017 4th International Conference on Information Technology, Computer, and Electrical Engineering, ICITACEE 2017, 2017, hal. 127-130.

[27] C.W. Yu dan A.K. David, "Pricing Transmission Services in The Context of Industry Deregulation,” IEEE Trans. Power Syst., Vol. 12, No. 1, hal. 503-510, 1997.

[28] E. Saranya dan P.L. Somasundaram, "Short Run Marginal Cost Calculation in Restructured Power System,” ICACCS 2015 - Proc. of the 2nd International Conference on Advanced Computing and Communication Systems, 2015, hal. 1-5.

[29] Y.R. Sood, N.P. Padhy, dan H.O. Gupta, "Assessment for Feasibility and Pricing of Wheeling Transactions Under Deregulated Environment of Power Industry,” Int. J. Electr. Power Energy Syst., Vol. 26, No. 3, hal. 163-171, 2004.

[30] J. Wang dan F. Li, "LRMC Pricing Based on MW + MVAR Miles Methodology in Open Access Distribution Network," C I R E D 19th International Conference on Electricity Distribution, 2007, Paper 0790, hal. 21-24.

[31] C.W. Yu, "Long Run Marginal Cost Based Pricing of Interconnected System Wheeling,” Electr. Power Syst. Res., Vol. 50, No. 3, hal. 205-212, 1999.

[32] F. Li dan D.L. Tolley, "Long-Run Incremental Cost Pricing Based on Unused Capacity,” IEEE Trans. Power Syst., Vol. 22, No. 4, hal. 16831689, 2007.

[33] B. Kharbas, M. Fozdar, dan H. Tiwari, "Transmission Tariff Allocation Using Combined MW-Mile \& Postage Stamp Methods,” 2011 IEEE PES International Conference on Innovative Smart Grid Technologies-India, ISGT India 2011, 2011, hal. 6-11.

[34] A. Scarfone, "Short-Circuit Simulations Help Quantify Wheeling Flow," IEEE Comput. Appl. Power, Vol. 8, No. 2, hal. 44-47, 1995.

[35] C.M. Kishore dan C. Venkaiah, "Implementation of Modified MW-Mile Method for Transmission Cost Allocation by Incorporation of Transmission Losses Considering Power Factor,” 2016 Natl. Power Syst. Conf., 2016, hal. 1-4.

[36] G. Jain, K. Singh, dan D.K. Palwalia, "Transmission Wheeling Cost Evaluation Using MW-Mile Methodology,” 2012 Nirma University International Conference on Engineering (NUiCONE), 2012, hal. 1-6.

[37] C.T. Su dan J.H. Liaw, "Power Wheeling Pricing Using Power Tracing and MVA-KM Method," 2001 IEEE Porto Power Tech Proceedings, 2001, hal. 38-43.
[38] Y.R. Sood, N.P. Padhy, dan H.O. Gupta, “A New Method for Allocating Embedded Cost of Transmission Under Deregulated Environment of Power System,” 2006 IEEE Power Eng. Soc. Gen. Meet., 2008, hal. 1-8.

[39] J. Das dan S. Ashok, "Industrial Power Wheeling and Optimal Power Interchange Under Availability Based Tariff,” Proc. - 2013 3rd Int. Conf. on Advances in Computing and Communications, ICACC 2013, 2013, hal. 320-323.

[40] M. Murali, M.S. Kumari, dan M. Sydulu, "A Comparison of Fixed Cost Based Transmission Pricing Methods," Electrical and Electronic Engineering, 2011, Vol. 1, No. 1, hal. 33-41.

[41] S. Venkatesan dan N. Kamaraj, "Deregulated Environment IPP Selection Wheeling Transaction,” J. Electr. Eng., Vol. 13, No. 3, hal. 1-7, 2013.

[42] A.S. Mishra, G. Agnihotri, N.P. Patidar, "Transmission and Wheeling Service Pricing: Trends in Deregulated Electricity Market,” J. Adv. Eng. Sci., Vol. 3, No. 1, hal. 1-16, 2010.

[43] M. Fotuhi-Firuzabad, H. Gharagozloo, M.R. Haghifam, S. Member, H. Gharagozloo, dan M.R. Haghifam, "Impacts of Power Wheeling on Composite System Adequacy Enhancement," Proc. of the IEEE Power Engineering Society Transmission and Distribution Conference, 2005, hal. $1-5$.

[44] S. Cvijic dan M. Ilic, "Area-Level Reduction of Wheeling Loop Flows in Regional Power Networks," IEEE PES Innovative Smart Grid Technologies Conference Europe, 2012, hal. 1-8.

[45] Y.Z. Li dan A.K. David, “Optimal Multiarea Wheeling,” IEEE Trans. Power Syst., Vol. 9, No. 1, hal. 288-294, 1994.

[46] M. Muchayi, "Wheeling Rates Evaluation Using Optimal Power Flows," IEEE Canadian Conference on Electrical and Computer Engineering, 1998, hal. 389-392.

[47] T. Yong dan R. Lasseter, "Optimal Power Flow Formulation in Market of Retail Wheeling,” IEEE Power Eng. Soc. 1999 Winter Meet. (Cat. No.99CH36233), 1999, hal. 394-398.

[48] N.P. Padhy, "Wheeling Using Evolutionary Programming Based Optimal Power Flow Algorithm," Proc. of $5^{\text {th }}$ Int. Conf. on Advances in Power System Control, Operation and Management, APSCOM-2000, 2000, hal. $144-148$.

[49] Y.R. Sood, N.P. Padhy, dan H.O. Gupta, "A New Hybrid Model for Wheeling Cost Analysis under Deregulated Environment,” IEEE PES Transmission and Distribution Conference and Exposition (IEEE Cat. No.03CH37495), 2003, hal. 97-102.

[50] D. Shirmohammadi, "Some Fundamental Technical Concepts about Cost Based Transmission Pricing,” IEEE Trans. Power Syst., Vol. 11, No. 2, hal. 1002-1008, 1996.

[51] Z. Yang, H. Zhong, Q. Xia, C. Kang, T. Chen, dan Y. Li,, "A Structural Transmission Cost Allocation Scheme Based on Capacity Usage Identification,” IEEE Trans. Power Syst., Vol. 31, No. 4, hal. 2876-2884, 2016.

[52] F. Jonard, Y. Smeers, P. Bruel, dan B. Heilbronn, "Wheeling Costs: An Economic Analysis Illustrated by Short Term and Long Term Simulation," International Symposium on Electric Power Engineering, 1995, Vol. 27, No. 10, hal. 692-697.

[53] J.W.J. Wang dan F.L.F. Li, "Optimal Economic Environmental Dispatch Considering Wheeling Charge," 39th International Universities Power Engineering Conference, 2004, UPEC, 2004, hal. 398-401.

[54] G.R. Yousefi, H. Seifi, "Wheeling Charges with Consideration of Consumer Load Modeling," in IEEE PES, Power Systems Conference and Exposition, 2004, hal. 168-173.

[55] D. Gang, Z.Y. Dong, W. Bai, dan X.F. Wang, "Power Flow Based Monetary Flow Method for Electricity Transmission and Wheeling Pricing,” Electr. Power Syst. Res., Vol. 74, No. 2, hal. 293-305, 2005.

[56] Y.Z. Li dan A.K. David, "Wheeling Rates of Reactive Power Flow under Marginal Cost Pricing," IEEE Trans. Power Syst., Vol. 9, No. 3, hal. 1263-1269, 1994.

[57] R.R. Fauzi, H.R. Prima, S.P. Hadi, dan Y.S. Wijoyo, "Power Wheeling Cost Evaluation under Contingency Condition using Tracing Method," AIP Conference Proceedings, 2016, hal. 1-6.

[58] E.L. Silva dan S.E.C. Mesa, "Transmission Access Pricing to Wheeling Transaction: A Reliability Based Approach,” IEEE Trans. Power Systcm, Vol. 13, No. 4, hal. 1481-1486, 1998. 
[59] N.A. Mijuskovic, "Reliability Indices for Electric-Power Wheeling," IEEE Trans. Reliab., Vol. 43, No. 2, hal. 207-209, 1994.

[60] S. Larbwisuthisaroj dan S. Chaitusaney, "Wheeling Charge Considering Line Flow Differentiation based on Power Flow Calculation,” 2018 - 15th International Conference on Electrical Engineering/Electronics, Computer, Telecommunications and Information Technology (ECTICON), 2018, hal. 293-296.

[61] M.V.F. Pereira, B.G. Gorenstin, M.M. Fo, dan J.B. Silva, “Chronological Probabilistic Production Costing and Wheeling Calculations with Transmission Network Modeling,” IEEE Trans. Power Syst., Vol. 7, No. 2, hal. 885-891, 1992.

[62] S. Nojeng, M.Y. Hassan, D.M. Said, M.P. Abdullah, dan F. Hussin, "Improving the MW-Mile Method Using the Power Factor-Based Approach for Pricing the Transmission Services," IEEE Trans. Power Syst., Vol. 29, No. 5, hal. 2042-2048, 2014.

[63] S. Sahay, N. Kumar, dan H. Joshi, "Modified MW Mile Method for Pricing the Transmission Services by Including Transmission Losses and Variation in the Load Power Factor,” Proc. - 2018 Int. Conf. on Smart Electric Drives and Power System, ICSEDPS 2018, 2018, hal. 267-271.

[64] T. Niimura, K. Okada, R. Yokoyama, dan N. Okada, "Multiple-Impact Assessment of Wheeling and Independent Power Producers In a DeRegulated Power System," IEEE Canadian Conference on Electrical and Computer Engineering, 1998, hal. 89-92.

[65] B. Liu, Y. Liu, dan T. Inaba, "A New Wheeling Price Calculation Method Considering Transmission Line Congestion and Loss Costs," 2004 Int. Conf. on Power System Technology, PowerCon 2004, 2004, hal. 12011206.

[66] A.G. Vlachos dan P.N. Biskas, "Supporting Services for Real Time Wheeling Transactions Requests,” 2011 16th International Conference on Intelligent System Applications to Power Systems, ISAP 2011, 2011, hal. 1-6.

[67] M. Zhou, G. Li, Y. Zheng, J. Yang, dan J. Qi, “An Integrated Approach on Allocating the Fixed Wheeling Cost of Large Consumers Considering Time-of-Use Pricing and Power Quality,” Proc. 2007 IEEE Lausanne Power Tech, 2007, Paper 616, hal. 920-925.

[68] S. Rajasekaran dan S. Sathiyamoorthy, "Power Flow Analysis of Restructured Power Market with Wheeling Transactions for Variable Loads,” Int. J. Sci. Eng. Appl. Sci., Vol. 2, No. 9, hal. 158-167, 2016.

[69] T. Sackey dan S.Z. Zakhary, "Power Wheeling Through the West African Interconnected System,” Sixth Int. Conf. AC DC Power Transm., 1996, No. 423, hal. 13-18.

[70] S.P. Zhu, "Some Considerations on Transmission Services Concerning Optimizing Wheeling Parties’ Benefits,” Proc. 1995 Int. Conf. on Energy Management and Power Delivery EMPD '95, 1995, hal. 19-24.

[71] Wahyuda, B. Santosa, dan A. Rusdiansyah, "Cost Analysis of An Electricity Supply Ehain Using Modification of Price Based Dynamic Economic Dispatch in Wheeling Transaction Scheme,” IOP Conference Series: Materials Science and Engineering, 2018, Vol. 337, hal. 1-7.

[72] Y. Tsukamoto dan I. Iyoda, "Allocation of Fixed Transmission Cost to Wheeling Cooperative Game Theory,” IEEE Trans. Power Syst., Vol. 11, No. 2, hal. 620-629, 1996.

[73] A.R. Abhyankar, S.A. Soman, dan S.A. Khaparde, "Optimization Approach to Real Power Tracing: An Application to Transmission Fixed Cost Allocation,” IEEE Trans. Power Syst., Vol. 21, No. 3, hal. 13501361, 2006.

[74] X. Gao, P. You, dan M. Wen, "Fixed Cost Allocation Based on Current Electro- magnetic Fields on Power Market," 2018 2nd IEEE Conf. Energy Internet Energy Syst. Integr., 2018, hal. 1-4.

[75] J.W.M. Lima, "Allocation of Transmission Fixed Charges: An Overview," IEEE Trans. Power Syst., Vol. 11, No. 3, hal. 1409-1418, 1996.
[76] Y.M. Park, J.B. Park, J.U. Lim, dan J.R. Won, “An Analytical Approach for Transaction Costs Allocation in Transmission System,” IEEE Trans. Power Syst., Vol. 13, No. 4, hal. 1407-1412, 1998.

[77] J. Bialek, "Tracing The Flows of Electricity," IEE Proc. - Generation, Transmission and Distribution, 1996, Vol. 143, No. 4, hal. 313-320.

[78] D. Kirschen, R. Allan, dan G. Strbac, "Contributions of Individual Generators to Loads and Flows," IEEE Trans. Power Syst., Vol. 12, No. 1, hal. 52-60, 1997.

[79] W. Xi-fan, W. Xiu-li, dan J. Bin, "Power Tracing Analysis in Wheeling Costing," Int. Conf. on Electric Utility Deregulation and Restructuring and Power Technologies, 2000, hal. 173-178.

[80] B. Khan dan G. Agnihotri, "An Approach for Transmission Usage \& Loss Allocation by Graph Theory,” WSEAS Transactions on Power Systems, Vol. 9, hal. 44-53, 2014.

[81] N. Yamaguchi, I. Takahashi, H. Kita, dan K. Nishiya, dan J. Hasegawa, "An Allocation of Wheeling Costs in Power Systems with FACTS Devices," Proc. of Int. Conf. on Electric Utility Deregulation and Restructuring and Power Technologies, 2000, hal. 549-553.

[82] T. Ogawa, S. Kadota, dan S. Iwamoto, "Transmission Line Loss Allocation Using Power Flow Tracing with Distribution Factors,” 2007 IEEE Power Engineering Society General Meeting, 2007, hal. 1-7.

[83] E. Telles, D.A. Lima, J. Contreras, dan N. Alguacil,, "A New Transmission Tariff Allocation Model Based on Bilevel Programming," IEEE Trans. Power Syst., Vol. 32, No. 3, hal. 2204-2213, 2017.

[84] P. Panyakaew dan P. Damrongkulkamjorn, "Optimal Loss Allocation of Multiple Wheeling Transactions in a Deregulated Power System,” Proc. of ICECE 2008 - 5th International Conference on Electrical and Computer Engineering, 2008, hal. 343-348.

[85] O. Pop, S. Kilyeni, P. Andea, C. Barbulescu, dan C. Craciun, "Power Flow Tracing Method for Electricity Transmission and Wheeling Pricing," J. Sustain. Energy, Vol. 1, No. 4, hal. 63-70, 2010.

[86] A. Enshaee dan P. Enshaee, "New Reactive Power Flow Tracing and Loss Allocation Algorithms for Power Grids using Matrix Calculation,” Int. J. Electr. Power Energy Syst., Vol. 87, hal. 89-98, 2017.

[87] H. Shareef, S.A. Khalid, M.W. Mustafa, dan A. Khairuddin, "Preference Comparison of AI Power Tracing Techniques for Deregulated Power Markets,” Adv. Artif. Intell., Vol. 2012, hal. 1-9, 2012.

[88] S.H.M. Kerta, Z.A. Hamid, dan I. Musirin, "Real Power Generation Tracing for Deregulated Power System Using the Flower Pollination Algorithm Technique,” J. Theor. Appl. Inf. Technol., Vol. 81, No. 3, hal. 564-578, 2015.

[89] A. Saxena, S.N. Pandey, dan L. Srivastava, "Genetic Algorithm based Wheeling Prices Allocation for Indian Power Utility by using MVA-Mile and MW-Mile Approaches," Int. Conf. on Emerging Trends in Electrical, Electronics and Sustainable Energy Systems, ICETEESES 2016, 2016, hal. 60-63.

[90] N.V.S. Rao, G.K. Rao, dan S. Sivanagaraju, "Transmission Loss Allocation with Optimal Power Flow using Gravitational Search Algorithm," Int. J. of Innovative Research in Electrical, Electronics, Instrumentation and Control Engineering (IJIREEICE), Vol. 2, No. 10, hal. 2117-2126, 2014.

[91] M.S.S. Rao dan S.A. Soman, "Marginal Pricing of Transmission Services Using Min-Max Fairness Policy,” IEEE Trans. Power Syst., Vol. 30, No. 2, hal. 573-584, 2015.

[92] G.V Narayana dan G.V.S.K. Rao, "Computationally Efficient Optimal Power Flow Tracing," Int. J. of Adv. Scientific Technologies, Engineering and Management Sciences (IJASTEMS), Vol. 3, Spec. Issue. 1, hal. 2028, 2017. 